\title{
Thinking outside four walls: the case for reconfiguring traditional
}

\section{classrooms}

\section{Nicole Dingwall*}

*Department of Educational Studies, University of Oxford, Oxford, United Kingdom.

15 Norham Gardens, Oxford, OX2 6PY Nicole.dingwall@education.ox.ac.uk

Orcid: ID http://orcid.org/0000-0002-8300-3260

Nicole Dingwall is the Lead Curriculum Tutor on the PGCE English course at the University of Oxford. Previously Nicole taught English in secondary schools in Australia and the UK. She is currently conducting research on the cultures of secondary school English departments. Her research interests include teachers' identities, vulnerable children inside and outside education along and with literacy. 


\section{Thinking outside four walls: the case for reconfiguring traditional classrooms}

This article explores the affordances provided by altering the way in which a traditional structured classroom is perceived. The article, through an exploration of reconfiguring a classroom space in a drama intervention, outlines the affordances provided to young vulnerable people and the adults that they work with. Such reconfigurations are essential in order to provide vulnerable young people with the means to alter the stereotype that have been assigned to them by others. Equally the reconfiguration is a tool that can equip the adults with the space to better understand the young people and their backgrounds. Together this can allow a differing identity to flourish and provide young vulnerable people with the space to evolve into their true self. Altering or defamiliarisng the space affords a potential relational change for both students and adults.

Keywords: Affordance; Drama Intervention; Vulnerable youth; Reconfiguring space.

\section{Introduction}

This article uses Gibson's (1977) concept of affordances to argue that the use of space in youth drama with vulnerable young people allows students to have control over their learning. Gibson focused on the ways that the environment could contribute to the development of thought and knowledge (Greeno, 1994). The research focus of this paper therefore applies the concept of affordance in order to investigate how young people viewed the physical boundaries that are implicit in schools in relation to their learning and the adults that they interacted with in these spaces.

Classrooms connote images of rows of desks and chairs facing the front of the classroom, implying a perception that teaching operates in one direction; the adult conveys information to the students. This perception both of the physical space and the role of the teacher restricts the teacher and student relationship; it suggests that the relationship only moves in one direction and therefore does not afford either the teacher or young adult the ability to shape and change the ways in which the teacher and student 
relationship can develop. Research has shown that reconfiguring classroom spaces provides numerous benefits to young people (Cooper 1993; Elliott and Dingwall 2017; Tawell, Daniels, Thompson, Elliott, Dingwall 2016; Thompson and Tawell 2017). Further, by reconfiguring classrooms, adults can engage with young people on a personal level by learning and understanding issues that are affecting young people which impacts on their learning.

The research sought to explore how the use of a space could enhance student learning and attitudes to learning and allow adults to gain a deeper understanding of the young people they were working with and, to some extent, provide an understanding of their behaviour. Evolving from this and guiding the research were the following questions:

1. What is affordance and does this provide a tool for adults and young peoples' relationships to shift?

2. Does an environment play a role in limiting the scope for relationships to develop?

3. Can a reconfigured space allow stereotypical narratives of young vulnerable people to be altered?

\section{Main text}

Gibson (1977) coined the term 'affordance' in a discussion regarding the affordances that an environment can give to animals. Greeno (1994) elaborates on the term's meaning by stating that it 'refers to whatever it is about the environment that contributes to the kind of interaction that occurs' (338). The affordances given to a classroom, once the space has been reconfigured, enables young people and adult relationships to evolve into one in which students feel they are able to gain respect from 
teachers and where both young and adult develop a deeper understanding of one another (Wilkin, Gulliver and Kinder, 2005). This affordance is not normally an aspect of the traditional classroom where 'A lot of teachers ... tell you this is what it is and how it will be' (Hughes and Wilson 2004, 63). The reconfigured space is beyond the realms of the traditional institutional space; thus it affords people occupying the reconfigured space to alter their behaviour and to become agentic in how they are perceived as they can choose how they behave and the presentation of this personality to others.

Hanrahan and Banerjee (2017) acknowledge that to develop the true self, there must be an emphasis placed on the importance of the environment around young vulnerable people. The environment should be supportive and essentially accept the individual as they are (Latting, 1990). Turner's (1974) concept of the liminoid provides a framework in which affordances can flourish, as these liminoid spaces operate within the structure of modern societies where time is allocated for the act of working and play. The latter affords the individual an opportunity to 'play', and, in this case, the play is the ability to alter and experiment with their true self in a space where rules are malleable. Hughes and Wilson (2004) state this is the space in which drama is conducted as an activity outside of the normal confines and regulations of an institution such as a classroom. Yet the aims remain similar to those of the institution: to develop and learn. Within this new space young people can engage in new experiences that allow them to be expressive and alter the predetermined nature of relationships with adults. By altering the space from the classroom to another space young people can safely engage in self-development; the new space has been reconfigured as the concept of the 'classroom', with its expectations, moves into a new realm.

Drawing on Moreno's (1959) role theory, individuals act in role in relation to the social context they find themselves in, e.g. in a classroom young people are students 
waiting to learn from the adult who is the teacher with knowledge to give. When applying role theory to the institution of schools, young people do not have the affordances to become agentic. The social context space in which they learn (Bandura, 1977) confines them to a certain role in which the expectations of them in relation to the norms are pre-established by the context of the space. Harkins et al.'s (2011) evaluation of theatre programmes in prisons in the United Kingdom showed that by reconfiguring a learning space, in this case the institution of a prison into an arts space, offenders were able to develop an understanding of themselves and others. The three day arts intervention benefitted the participants in that they felt more at '.. ease. You could relate to the people running it. It was nice to see the people running getting [sic] involved rather than having some tell you what to do and to get on with it' (Harkins et al., 2011, 558). Another participant commented that the programme had enabled him to now think before speaking in order to express himself. Both participants have learned in a space that has been changed; the rules, to some extent, of the prison had altered thereby affording the participants with a new way of learning and understanding.

The now defunct, though no less important message from The Social Exclusion Unit (2004) identified that strong relationships with parents, teachers and other adults is crucial in supporting and protecting young people. Therefore, the affordances given to support this development must be established in the way that society and governments view the space of classrooms.

By reconfiguring classrooms into 'safe spaces' (Elliott and Dingwall 2017, Thompson and Tawell 2017, Hughes and Wilson 2004) young people can: take risks; enter into dialogue with an adult that previously in a structured classroom would have been considered to be high risk; position themselves as vulnerable as they communicate their thoughts and feelings, a step they could not do previously. As a space is 
reconfigured, traditional boundaries between young people and adults begin to erode which encourages positive relationships to develop.

Young vulnerable people enrolled in traditional schooling are often stereotyped before they have a chance to demonstrate what they can do and who they are. The stereotypes surrounding these young people can often lead adults and others to act in a particular manner that is detrimental to the young person involved. These perceptions drive the actions and interactions of those involved with these young and vulnerable people. Brophy's (1983) research into the link between teacher behaviour and student expectations revealed a difference in teacher behaviour towards students they had high and low expectations of. He noted that only students with low expectations were rewarded for inappropriate behaviour, such as asking students to answer questions only when the teacher was certain the student knew the answer (650). Similarly, an adverse stereotype of young Maori students in New Zealand, that they lack a desire to learn, foregrounded teachers to perceive these students negatively (St George, 1983). The self-fulfilling prophecy (Cooper 1983, Good 1980), that being when an occurrence develops into a reality because of the belief that it will occur, does not afford these students with the ability to alter how they are perceived as they are in a space that does not operate outside the norms of the traditional classroom. They are unable to change these perceptions that drive the actions of others within the safe space that a reconfigured classroom could afford them.

Rosenthal and Jacobson's (1968) research into expectations in schools showed that students who are expected to achieve intellectually displayed greater intelligence than those students who had no expectations placed upon them during a one-year period. They summarise that 'one person's expectation for another's behaviour could come to serve as a self-fulfilling prophecy' (174). If all adults' expectations were 
favourable then possibly the outcome for all students could be improved. These expectations could be better developed by 'knowing' the student, and, for some, such as those in this research, knowing them should happen in a reconfigured classroom where the traditional expectations are not visible nor communicated and allow the individual student to flourish based on a new understanding gained by the adult. Hargreaves, Hester and Mellor (1975) questioned how a teacher comes to 'know' a student. They suggest that teachers engage in 'typing theory' where teachers speculate at the moment of their first contact and knowledge of the student. A teacher's knowledge of the student develops at the 'elaboration' (145) stage and finally the knowledge stabilises upon the teacher having a clear sense of the student's identity. The difficulty for students who are already marginalised is that the speculative stage can often shape the views of the teacher whose knowledge of that student is already one who is a 'problematic student'. As the Hargreaves, Hester and Mellor (1975) research indicates, teachers label students, and one of those is in relation to 'conformity to discipline role' with terms used such as 'difficult ... disruptive' (147) These concepts, often attributed to students on the periphery, at the elaboration stage, are when a teacher will either confirm their opinion or not. Therefore, it is essential for these students to be given an opportunity to be 'known' in a different sphere then the classroom space to be given a chance to change the view before it becomes entrenched.

A reconfigured classroom allows students and adults to reset themselves, to redefine how each other views one another instead of, as Brook (1968) suggested, 'defin[ing] how the play should be done' (14). The literature has indicated the ways in which a classroom space is viewed can hinder young vulnerable people's chance to escape from preconceived notions that others have of them. Equally the affordances granted through reconfiguring the sense of classroom space ensures that adults are able 
to develop a greater knowing of the young vulnerable people they work with thereby altering their perceptions of the young people.

Valentine (2000) noted that student identities are negotiated in multiply ways and one is through the overlooked spaces that are not subjected to adult supervision in the way the classroom is and can allow for incidental opportunities to surface. In light of this alternate learning environments can create a space for vulnerable young people to negotiate their identities as there is limited space in schools for students to enter into such activity (Kraftl, 2013). Such alternative spaces have included care farms, forest schools, homeschooling, democratic and human scale schooling, Steiner schools, Montessori schools, these spaces mark themselves as alternate because they are in contrast to mainstream schooling. Yet Kraftl (2013) posits that more often these alternate learning environments connect with many of the organisations that mainstream schools do, for example, the local authority and I argue are therefore integrated into the trappings of a mainstream schools. Despite this the alternate learning environments can offer such overlooked spaces in which vulnerable young people can negotiate their identities (Valentine, 2000) as incidental opportunities can arise for the young person and adult to engage in unstructured and informal communication, where barriers may not exist as they do in formal settings. Therefore, the traditional concept of what constitutes a classroom ought to be reconfigured.

\section{Methods}

This research was conducted through various qualitative methods in order to understand the perspective of the young people and the key workers. Qualitative research methods involving observations and interviews were deemed appropriate due to the personal nature of the research questions; the questions sought to understand and 
explain the personal perspectives of the experiences of those involved in the research (Merriam and Tisdell, 2016). The interactions between the key workers and the young people in a reconfigured space was the focus of the research and to explore these human interactions it was necessary to engage in qualitative research; an approach used to understand meaning with in the social context (Litchman, 2017). In addition, the research is drawn from a larger subset of data that formed a larger evaluation of the effectiveness of art based interventions (Tawell et al., 2015). A local community theatre company selected four programmes for the researchers to access; these consisted of two 8 week interventions in a local school and two extracurricular events located with the space of the local theatre. These programmes were chosen by the theatre company as they were interventions that focused on young vulnerable people.

The intervention site school was a larger than average inner city school with an intake from a wide variety of ethnic backgrounds. The proportions of students supported by the pupil premium (government funding to support disadvantaged students) and with special educational needs were both above the national average. The school intervention groups consisted of two groups of students aged between 11 and 12 years. Within each group were seven students. These students participated in the programme for 7 weeks. Each session was conducted on the school premises and lasted for an hour and a half. The selection of students to the programme was decided by the school on two criteria. For the first group it was linked to behavioural issues, such as lateness, being disruptive in class or truanting. The second group consisted of students who were either young carers or classified vulnerable. The location of the sessions for the two groups was different; group 1 attended the theatre whilst group 2 remained in school and the sessions were convened in numerous places but mainly in a mathematics classroom that enabled an open space to be created. 
The theatre group, The Other Side, aimed to support young women who were considered to be vulnerable. The young women ranged in ages from 12-20 years. 6 of the 8 young women who attended the sessions were in secondary school. All students were invited to be interviewed and those interviewed were the students who gave consent. Over the period of time the fieldwork was conducted, four adults led the group and they were interviewed by a colleague as these four adults were not only responsible for this group but for the other groups located within the realm of the theatre. This group met weekly, with all meetings in the café of the theatre prior to the commencement of the session. This space allowed the group leaders to touch base with all of the participants and for each other to catch up. Following this the young women engaged in a one-hour drama session where they were constructing a piece to perform to family and friends.

Plus One was a weekly programme in the theatre run during a school academic year. The theatre consciously selected young people who fell into two groups: vulnerable and less vulnerable, they were aged between 12 and 18 years. Some students were referred by social services. Some of the less vulnerable young people had a pre-existing connection with the theatre or with another theatre and these young people collectively were selected as peer mentors. All names of the groups have been changed and all young people have been given a pseudonym.

Five researchers, including the author, engaged in field work with the various groups where one or two researchers attended one or more of the weekly programmes. Researchers engaged with the groups as: participant observers through our actions and by participating in activities; and as leaders in our roles of adults participating in the activities as directed by the group leaders; at no point did the researchers deliver the 
programmes in any of the sites. The group leaders often directed our role within the group, supporting young people to complete tasks such as their booklet for the Arts Award. Through the continual weekly participation, the researchers developed relationships with the young people that enabled the data to be richer as they shared their feelings, emotions and thoughts with us. Field notes were written at the end of each session. The young people participated in a 20 min individual structured interview at the end of the programme. On some programmes group interviews were conducted, a few structured evaluations tasks were completed and the group leaders were interviewed at the beginning and end of the research. The interview data was transcribed and thematically coded independently by three of the researchers. The researchers then developed codes based on identification of the repetition of related themes from the transcripts of the interviews (Saldana, 2016). Patterns emerged from the data in relation to the interview questions and the following codes emerged: confidence; self-esteem; positive staff and peer relationships; communication skills; resignification; and success. This was an inductive process that was informed in particular by Cooper's (1993) classification of the three "R's" in effective interventions aimed at troubled young people; respite, relationships and resignification. As the data emerged from interviews with young vulnerable students it was not appropriate to re-engage in forms of respondent validity measures. However, to ensure the validity of the data, the research team discussed the data transcripts and analysis of the interviews.

\section{Ethics}

The University of Oxford's Central University Research Ethics Committee granted ethical approval. Further the research team followed the British Educational Research Association Ethical Guidelines for Educational Research (BERA, 2011). 
Informed consent was sort and granted by the participants, their parents or guardians and the group leaders. The young people were reminded that they could withdraw or choose to not answer questions at the beginning of the interviews and the majority were keen to share their thoughts and ideas regarding their experiences. Pseudonyms have been used in place of the research participants A majority of the young people involved were vulnerable and throughout the research, as researchers, we were privy to sensitive material. Researchers treated these young people with sensitivity, dignity and without judgement.

\section{Results}

Josie, one of the young people, commented that the space of a drama studio allowed her to contribute to her learning in a different way than that associated with school: we go out and do things we're in different rooms, and we do more pro-active stuff, and everybody has an input into everything. So if that was able to do in the class, that would be awesome. Josie went on to say that this allowed her to connect with people in her class who she would not normally talk with and this would make learning in classes easier.

The reconfigured classroom enabled the young people to view the adults differently, there was a greater appreciation of the adults, Sam commented: ... we have to take care of other people because like if they're [the adults] looking out for you then there's no point in you just being rude and disrespectful because they're basically using up their time to spend time with us and yeah. This sentiment was corroborated by another young person Ned, in a different group who noted the contrast of the role of the adult in two different spaces; The support they give you, and the fact that they listen to you and try, and help you as much as they can,... but with school they don't really, they just get you through it, and just get rid of you at the end of the day. The common theme 
emanating from the young people was the support and time given to them by adults in the reconfigured space was appreciated as it allowed them to voice their concerns and opinions.

Eve, another young person, noted that the reconfigured space afforded her the opportunity to step out from the boundaries that the school space had placed on her identity:

Like I said, more freedom, like you can express yourself in your own way, not like in the school way, because you're told to be in a certain way aren't you? And you have to be that person, but here you can just let yourself out and do it. So I found that much more space.

Here it seems that Eve's 'shackles' are inevitable in the school space in which she is are limited by those who perceive her in a certain way.

Lisa, an adult mentor, commented that the space altered the behaviour and attitude of the young people:

I think being in a professional theatre, they really do kind of rise to it, there are other people in the building it's not just about them and suddenly they take on a bit of responsibility about their behaviour and how they're supposed to act in a building.

The reconfigured space enabled the young people to develop and this level of responsibility carried over into their learning and collaboration with others.

One of the groups walked between the school space and the drama space and it was during this time that the adults developed an awareness and understanding of the young people beyond the walls of a classroom. Lewis commented it was:

quite interesting to see for us on the walks up and down and talking to the kids it was a great talk for finding out what was actually going on at home and things like this 
... because we were finding out all this stuff in the groups ... it gives an opportunity for chat really, just very one to one, walking and talking.

Ben, another adult involved in the escorting of young people to the theatre, noted the young people: have to kind of deal with this sort of [trauma] and that's kind of quite interesting to see for us on the walks up and down and talking to the kids it was a great talk for finding out what was actually going on at home and things like this. The reconfigured space afforded the adults the opportunity to know and learn more about the young people's lives and altered their perceptions regarding the young people

One adult, Dave, commented that the reconfigured space allowed the young people to shake off reputations, the label given to them at school and to reset themselves as a different person who is able to learn and is viewed objectively: bringing any of them out of their school environment they can let go of the label so I'm the naughty one, here nobody knows me... they are still going to have barriers... this is a different way of doing anything so they are learning but it's not sitting down. Here the learning goes beyond subject learning, the young people are learning to be full participants in society.

The adults felt that in the reconfigured classroom there was an opportunity to create a safe space as Bethan stated: what they get out of that kind of balanced relationship is, is that sense of belonging and that citizenship that I spoke about before, that democratisation, that ability to kind of have an impact on, on what happens at the end. The space afforded the relationship between themselves and the young people to be on an equal footing: acknowledge that young person as um, as an individual in their own right who has uh knowledge, of the capacity for knowledge beyond that of the teacher.

\section{Discussion}


Much of the research on space within classrooms focuses on design of the classroom; there is a need to redefine how we conceptualise the notion of space within schools. Space does not refer merely to the physical space but moreover how individuals view the space as a means to extend the learning beyond the confines of the bricks and mortar of the school buildings. Not all traditional classrooms are appropriate for all students to learn in, therefore the term 'learning' needs to expand beyond learning that is in the remit of national curriculums.

The analysis of the data through the lenses of Gibson's affordances illustrated that space can be redefined in a manner that encourages perceptions to change. In this research the adult interactions with the vulnerable young people provided them with new insights to these young people; they were not simply being belligerent for its mere sake, they were vulnerable young people who needed support. Likewise, the affordance provided the young people a safe space that was conducive to allowing them agency as they could disclose what they chose when they wanted to.

Vulnerable young people often require respite from the difficulties of their personal and social lives that can cast a category upon them (Daniels and Downes 2014). However, they then struggle to emerge from this category. This research has indicated that through changing the way a space is figured can afford young people the opportunity to grow beyond the labels, 'here you can just let yourself out' and learn about themselves and others (Harkins et al. 2011) through the social interaction that drama provides. Interestingly drama does not need to occur in a drama studio but in a space that creates the environment that students can develop in, it is the way in which the space is used that is important to enable young people to develop, for the role in relation to the context it exits, to change (Moreno, 1959). 
The young people in this study found a new appreciation for each other (Wilkin, Gulliver and Kinder, 2005; Hughes and Wilson, 2004): the young people were afforded the chance to gain respect for the adults they were working with, they appreciated the time given to them by the adults and showed their respect by altering their behaviour illustrating their gratitude to the adults. The affordance the space generated was one in which the young people could offer their opinions in a manner beyond the confines of the classroom within the institution that is school.

The affordance provided by altering the space in which learning occurred ensured that the young people could develop their true self in a supportive environment (Hanrahan and Banerjee, 2017). The comments from the young people indicated they felt safe in the reconfigured space in which they were able to take risks such as exposing their thoughts because the adults were able to listen and work through these thoughts with the young people. In this sense the reconfigured classroom as a liminoid space (Turner, 1974) provides an arena for 'potentially socially transformative' (Spiegel 2011:13) practices to occur with a safe space (Elliott and Dingwall, 2017; Thompson and Tawell 2017) and enables the young people to develop positive relationships with adults.

Equally within the reconfigured space the adults gained a new perspective of the young people with a greater understanding of the lives of these young people. There was now an awareness of the difficult background that some of these young people exist in, and with such knowledge the interactions of the adults with these young people alters and therefore the perceptions change and they are longer viewed negatively (Brophy 1983, St George, 1983). The ability to gain a new perspective of these young people and interact differently affords the young person the chance to escape the 'selffulfilling prophecy' (Cooper 1979, Good 1980) as they are able to 're-set 'themselves 
and to alter the perception of adults and raise the expectations of them by the adults (Rosenthal and Jacobson 1983) thereby altering the actions of the adults.

\section{Conclusion}

This article has explored the affordances provided by altering the way in which a traditional structured classroom is perceived through an exploration of a reconfiguring of classroom space in a drama intervention. Affordances were provided to both young vulnerable people and the adults that they work with. Such reconfigurations are essential in order to provide vulnerable young people with the means to alter the stereotype that have been assigned to them by others. Equally the reconfiguration is a tool that can equip the adults with the space to better understand the young people and their backgrounds. Together this can allow a differing identity to flourish and provide young vulnerable people with the space to evolve into their true self. Altering or defamiliarisng the space affords a potential relational change for both students and adults.

\section{Acknowledgement}

This research was supported with investment from Artswork, the South East Bridge.

\section{Disclosure statement}

No potential conflict of interest was reported by the authors.

\section{References}

Bandura, A. (1977) Social learning theory. New York, NY: Prentice Hall 
BERA. 2011. Ethical Guidelines for Educational Research. London: BERA.

Brook, P. (1968) The Empty Space New York, NY: TOUCHSTONE

Brophy, J.E. (1983) Research on the Self-Fulfilling Prophecy and Teacher Expectation, Journal of Educational Psychology, 75(5) pp. 631-661.

Cooper, H. (1979) Pygmalion grows up: A model for teacher expectation communication and performance influence. Review of Educational Research, 49 pp. $389-410$.

Cooper, P. (1993) Exploring Pupils' Perceptions of the Effects of Residential Schooling on Children with Emotional and Behavioral Difficulties Child, Child \& Youth Care Forum 22(2) pp. 125-141.

Daniels, H. and Downes, E. (2104) Identity and creativity: The transformative potential of drama lessons, Journal of Modern Foreign Psychology, 3(2), pp.41-71.

Elliott, V, and Dingwall, N. (2017) Roles as a route to being 'other': drama-based interventions with at-risk students, Emotional and Behavioural Difficulties 22(1) pp. 66-78.

Gibson, J.J. (1977) The Theory of Affordances in The ecological approach to visual perceptions: classic edition Taylor and Francis

Good, T. (1980) Classroom expectations: Teacher-pupil interactions. In J. McMillan (ed.). The social psychology of school learning. New York: Academic Press.

Greeno, J.G., (1994) Gibson's Affordances, Psychological Review 101(2), pp. 336-342

Hanrahan, F. and Banerjee, R. (2017) 'It makes me feel alive': the socio-motivational impact of drama and theatre on marginalised young people'; Emotional and

Behavioural Difficulties, 22(1), pp. 35-49.

Harkins, L., Pritchard, C., Haskayne, D., Watson, A., and Beech, A.R. (2011)

'Evaluation of Geese Theatre's Re-Connect Program: Addressing Resettlement Issues in Prison; International Journal of Offender Therapy and Comparative Criminology 55(4) pp. 546-566 SAGE Publications.

Hargreaves, D.H., Hester, S.K. and Mellor, F.J. (1975) Deviance in classrooms London, Routledge \& Kegan Paul

Hughes, J, and Wilson, K. (2004) Playing a part: the impact of youth theatre on young people's personal and social development, Research in Drama Education, 9(1), pp. 5772.

Kraftl, P. (2013) Geographies of alternative education: Diverse learning spaces for children and young people, Oxford University Press 
Latting, J. K. (1990). Identifying the "isms": Enabling social work students to confront their biases. Journal of Social Work Education, 26(1), pp. 36-44.

Litchman, M., (2017) Qualitative Research for the Social Sciences London: Sage Publications.

Merriam, S. and Tisdell, E. (2016) Qualitative and Research A Guide to Design and Implementation Jossey-Bass San Francisco.

Moreno, J.L (1959) Psychodrama (Vol. 2) New York, NY: Beacon House

Rosenthal, R. and Jacobson, L. (1968) Pygmalion in the class- room: Teacher expectation and pupils' intellectual development. New York: Holt, Rinehart \&Winston.

St. George, A. (1983). Teacher expectations and perceptions of Polynesian and Pakeha pupils and the relationship to classroom behaviour and school achievement. British Journal of Educational Psychology, 53, pp.48-59

Saldana, J. (2016) The Coding Manual for Qualitative Researchers London: Sage Publications

Spiegel, A.D., (2011) Categorical difference versus continuum: Rethinking Turner's liminal-liminoid distinction, Anthropology Southern Africa, 34(1-2), pp.11-20.

Tawell, A., Thompson, I., Daniels, H., Elliott, V. Dingwall N. with Rubtsova, O. and Munk, K. (2015) Being Other: The Effectiveness of Arts Based Approaches in Engaging with Disaffected Young People.

The Social Exclusion Unit (2004) Breaking the Cycle Taking stock of progress and priorities for the future, Office of the Deputy Prime Minister, London

Turner, V. (1974) 'Liminal to liminoid, in play, flow, and ritual: an essay in comparative symbology’ Rice Institute Pamphlet-Rice University Studies, 60(3).

Thompson, I. and Tawell, A. (2017) Becoming other: social and emotional development through the creative arts for young people with behavioural difficulties, Emotional and Behavioural Difficulties 22(1) pp 18-34.

Valentine, G. (2000) 'Exploring children and young people's narratives of identity', Geoforum, vol 31, pp 257-67.

Wilkin, A, Gulliver, C., and Kinder, K. (2005) Serious Play An evaluation of arts activities in Pupil Referral Units and Learning Support Units, Calouste Gulbenkian Foundation 